\title{
Use of Colletotrichum graminicola KA001 to Control Barnyard Grass
}

Young-Kook Yang, Soon-Ok Kim, Hoo-Sup Chung, and Yong-Hwan Lee, School of Applied Biology and Chemistry, Research Center for New Bio-Materials in Agriculture, Seoul National University, Suwon 441-744, Korea

\begin{abstract}
Yang, Y.-K., Kim, S.-O., Chung, H.-S., and Lee, Y.-H. 2000. Use of Colletotrichum graminicola KA001 to control barnyard grass. Plant Dis. 84:55-59.

Isolates of Colletotrichum graminicola were obtained from barnyard grass showing anthracnose symptoms and the fungus was evaluated as a potential biocontrol agent. C. graminicola KA001 was highly pathogenic to two varieties of barnyard grass in a wide range of growth stages, with the most damage at the three- to four-leaf stages. Disease severity of barnyard grass increased with the increase of the inoculum density from $1 \times 10^{4}$ to $1 \times 10^{5}$ conidia $/ \mathrm{ml}$, but inoculum density above $1 \times 10^{6}$ conidia/ml did not increase disease severity. A total of 13 rice cultivars tested showed no disease symptoms when inoculated with this fungus. Appressoria were formed on both barnyard grass and rice leaves, but infection hyphae were only found in the cells of barnyard grass. The fungus grew and sporulated in a wide range of temperature regimes, with optimal temperature at 27 to $30^{\circ} \mathrm{C}$. These data suggest that $C$. graminicola KA001 has potential as a mycoherbicide to control barnyard grass with a safe selectivity in rice fields.
\end{abstract}

Additional keywords: biological control, Echinochloa crus-galli var. caudata, E. crus-galli var. praticola, Oryza sativa

Rice (Oryza sativa L.) is one of the most important food sources in the world, especially in Asian countries. However, stable production of rice has been limited by many diseases, insects, and weeds. Recently, weed problems in rice paddy fields have increased drastically as affected by the change in the cultural pattern of transplanting into direct-seeding methods in Korea (17). Two- to threefold more weeds were harvested in the direct-seeded rice fields than in transplanting fields. In addition, the weed flora of dominant species shifted toward C4-type grass weeds (19). The most troublesome weed in directseeded rice is barnyard grass (Echinochloa crus-galli var. praticola and E. crus-galli var. caudata), and a high yield loss due to competition with barnyard grass has been reported in Korea (20). Herbicides have been widely used to manage barnyard grasses in rice fields, but residual toxicity and other deleterious effects of chemicals require alternative strategies to control weeds in the fields.

Corresponding author: Y.-H. Lee

E-mail: yonglee@plaza.snu.ac.kr

This work was supported by the Korea Science and Engineering Foundation through the Research Center for New Bio-Materials in Agriculture at Seoul National University.

Accepted for publication 16 September 1999.

Publication no. D-1999-1101-01R

(c) 2000 The American Phytopathological Society
Biological control of weeds is an alternative approach, utilizing living organisms to control or reduce the population of undesirable weed species. The classical approach with exotic plant pathogens to control weeds was developed in the beginning of the 1970s (2). Puccinia chondrillina was used effectively to control skeleton weed (Chondrilla juncea) in Australia and the United States (1,6,15). Entyloma ageratinae was effective in controlling mistflower (Ageratina riparia) in Hawaii (4). An alternative approach to bioherbicide development is based on the idea that an endemic (i.e., native) pathogen might control its weed hosts through a massive dose of inoculum at susceptible stages of weed growth $(11,14)$.

Much research on the development of new mycoherbicides has been conducted during the past decade worldwide. Among the candidates for mycoherbicides, Colletotrichum spp. especially have undergone extensive testing for commercial development (27). These include C. gloeosporioides f. sp. aeschynomene for northern jointvetch (Aeschynomene virginica; 7,14), C. coccodes for velvet leaf (Abutilon theophrasti; 24,31), C. orbiculare for spiny cocklebur (Xanthium spinosum; 3,23), C. gloeosporioides f. sp. jussiae for winged water primrose (Jussiaea decurrens; 9); $C$. malvarum for prickly sida (Sida spinosa; 21), C. truncatum for hemp sesbania (8), and $C$. capsici for pitted morning-glory (Ipomoea lacunosa; 10). C. graminicola isolated from johnson grass (Sorghum halepense) was also evaluated as a potential mycoherbicide (12), but no at- tempt was reported to control barnyard grass.

We report here that $C$. graminicola KA001 isolated from foliar anthracnose lesions on barnyard grass has the potential as a mycoherbicide to control barnyard grass in rice paddy fields.

\section{MATERIALS AND METHODS}

Isolation of fungi. Isolates of $C$. graminicola were obtained from barnyard grass showing anthracnose symptoms in rice paddy fields in the Chuncheon and Kapyeong areas in Korea during August and September of 1994. Symptomatic leaves were surface sterilized with $3 \%$ sodium hypochlorite and placed on water agar (WA). Mycelial blocks from WA were transferred on potato dextrose agar (PDA) and incubated at $27^{\circ} \mathrm{C}$. Single-spore isolates were maintained on potato carrot agar (PCA). Three isolates of $C$. graminicola (CH001, CH002, and KA001) were preliminarily tested for pathogenicity to barnyard grass. C. graminicola KA001 was the most pathogenic and used in the following study.

Plant growth and inoculum production. Seeds of barnyard grass (Echinochloa crus-galli var. praticola and E. crus-galli var. caudata) were collected from rice fields in the Experimental Farm at Seoul National University, Suwon, Korea. Dormancy was broken by placing the seeds at $10^{\circ} \mathrm{C}$ under damp conditions for 30 days. Low-temperature treatment is indispensable for the germination of barnyard grass seeds (25). Seeds of rice, other crops, and weeds were kindly provided by H. J. Koh at Seoul National University. Seeds were sown in commercial potting soil (Boonong Inc., Kyungbuk, Korea) in vinyl pots (5 $\mathrm{cm}$-diameter). Seeded pots were placed in the greenhouse until inoculation. Greenhouse conditions consisted of day and night temperatures of 35 and $23 \pm 3^{\circ} \mathrm{C}$, respectively, under natural light.

C. graminicola KA001 was grown on PDA for 7 days, and conidia were harvested by scraping the colony surface with an Eppendorf tube while rinsing it with distilled water. The suspension was passed through four layers of cheesecloth and rinsed three times with sterile distilled water. Spores were quantified with a hemacytometer and adjusted to the desired conidial concentration.

Pathogenicity tests of $C$. graminicola KA001 on barnyard grass. The two varieties of barnyard grass at different leaf 
stages (one to two, three to four, and five to six leaves) were inoculated with a conidial suspension of $C$. graminicola KA001 $\left(1.0 \times 10^{6} \mathrm{conidia} / \mathrm{ml}\right)$ in potato dextrose broth (PDB), placed in a dew chamber for $24 \mathrm{~h}$ at $30^{\circ} \mathrm{C}$, then transferred to a greenhouse. To study the effect of inoculum concentration, two varieties of barnyard grass at the three- to four-leaf stage were inoculated with four different concentrations of conidial suspensions (4.0, 5.0, 6.0, or $7.0 \mathrm{log}$ conidia/ml). Control plants were sprayed with PDB. Disease severity was rated 7 days after inoculation using the following scale: $0=$ no disease, $1=1$ to $20 \%$ diseased, $2=21$ to $50 \%$ diseased, $3=$ 51 to $70 \%$ diseased, $4=71$ to $90 \%$ diseased, and 5 = plants killed. These experiments were repeated twice with 10 plants per treatment.

Pathogenicity tests of $C$. graminicola KA001 on rice cultivars. A total of 13 rice cultivars, including the Japonica group (Ilpum, Chucheong, Nakdong, Dongjin, and Shinson), Tongil group (Nampung, Kaya, Hangang, and Tongil) and Indica group (IR-24, IR-36, IR-56, and IR-65), were tested. All rice plants at three- to four-leaf stages were inoculated with a conidial suspension $\left(1.0 \times 10^{6}\right.$ conidia/ml $)$ of $C$. graminicola KA001 in PDB. Inoculated plants were placed in a dew chamber for $24 \mathrm{~h}$ at $25^{\circ} \mathrm{C}$ and then transferred to the greenhouse. Symptom development was observed daily up to 7 days. These experiments were repeated twice with three plants per rice cultivar.

Host range of $C$. graminicola KA001. Crops (corn, soybean, rye, and barley) and weeds (alfalfa, henry crabgrass, panicum, red clover, and white clover) were used in range determination of $C$. graminicola KA001. A total of 10 plants of each crop and weed were inoculated with conidial suspension $\left(1.0 \times 10^{6}\right.$ conidia $\left./ \mathrm{ml}\right)$ in PDB. Inoculated plants were placed in a dew chamber at $30^{\circ} \mathrm{C}$ for $24 \mathrm{~h}$ and then transferred into the greenhouse. Disease severity was rated 7 days after inoculation with four disease rating scales: $-=$ no disease,+ $=$ approximately 1 to $30 \%$ diseased, $++=$ approximately 30 to $60 \%$ diseased, and $+++=>60 \%$ diseased. Each experiment was repeated twice.

Conidial germination, mycelial growth, and sporulation of C. graminicola KA001.

Table 1. Mycological characteristics of Colletotrichum graminicola KA001 on potato dextrose agar

\begin{tabular}{ll}
\hline Feature & \multicolumn{1}{c}{ Descriptiona $^{\mathbf{a}}$} \\
\hline Conidia & 17.1 to $34.3(25.9)$ by 4.3 to $7.1(5.8) \mu \mathrm{m}$ \\
Size & pale brown \\
Color & falcate \\
Shape & $\begin{array}{l}65.7 \text { to } 148.6(101.3) \text { by } 2.9 \text { to } 5.7(4.6) \mu \mathrm{m} \\
\text { Setae }\end{array}$ \\
Size & dark brown \\
Color & 1 to $6(2$ to 5$)$ \\
Septa & \\
\hline
\end{tabular}

${ }^{a}$ A total of 100 conidia and setae were measured. The numbers in parenthesis indicate the means of sizes.

Conidial germination, mycelial growth, and sporulation were observed at different temperatures $\left(15,20,25,27\right.$, or $\left.30^{\circ} \mathrm{C}\right)$. Conidial germination was examined at 12 $\mathrm{h}$ after inoculation by spreading $0.1 \mathrm{ml}$ of conidial suspension on PDA. A total of 100 conidia were counted with three replications per treatment. Mycelial growth was measured by colony diameter 14 days after incubation of a mycelial plug $(5 \mathrm{~mm}$ in diameter) on PDA. Sporulation ability of $C$. graminicola KA001 was measured 20 days after incubation by placing a mycelial plug ( $5 \mathrm{~mm}$ in diameter) on PDA. Distilled water $(15 \mathrm{ml})$ was poured into each plate and the plate was gently scraped with an Eppendorf tube. The conidial suspension was filtered through four layers of cheesecloth and concentration was measured with a hemacytometer. These experiments were repeated twice with four replications per treatment.

Histology of infection by $C$. graminicola KA001. Leaves of barnyard grass and rice were harvested 1,2 , and 7 days after inoculation and sectioned into squares $(0.5$ by $0.5 \mathrm{~cm}$ ). Each square was dechlorophyllized in an ethanol:chloroform (75:25, $\mathrm{vol} / \mathrm{vol}$ ) mixture containing $0.15 \%$ trichloroacetic acid, with frequent changes of the solution for $24 \mathrm{~h}$ at $25^{\circ} \mathrm{C}$. Leaf samples were stained with lactophenol-cotton blue for $20 \mathrm{~min}$, rinsed three times with distilled water, and observed under the light microscope (30). Appressorium development was also evaluated on artificial substrates, including hydrophobic and hydrophilic sides of Gelbond (FMC product, Rockland, ME), and at different $\mathrm{pH}$ levels ( $\mathrm{pH} \mathrm{4,} \mathrm{5,} \mathrm{6,} \mathrm{7,} \mathrm{8,} \mathrm{9,} \mathrm{or} \mathrm{10).} \mathrm{The} \mathrm{effects} \mathrm{of}$ the effector chemicals $\left(\mathrm{N}^{6}\right.$-monobutyryl cAMP at $10 \mathrm{mM}$ and 3-isobutyl-1-methylxanthine [IBMX] at $2.5 \mathrm{mM}$ ) on appressorium formation were also evaluated on Gelbond, as previously described (22). The percentage of germinated conidia and germinating conidia induced to form appressoria were determined from direct microscopic observation of at least 100 conidia per replicate in at least four experiments with three replications per treatment.

Statistical analysis. Analysis of variance was performed on the data with the PROC GLM procedure (SAS Institute, Cary, NC). If $P r>F$ was less than 0.01, means were separated with Duncan's multiple range test at the $P=0.05$ level.

56 Plant Disease / Vol. 84 No. 1

\section{RESULTS}

Isolation and identification of $C$. graminicola. The fungus isolated from barnyard grass showing anthracnose symptoms was identified as $C$. graminicola based on morphological and cultural characteristics. The colony of $C$. graminicola was orange in color at the beginning of incubation and then became grayish orange on PDA with diffuse and aerial fluffy mycelia 5 to 7 days after inoculation. The fungus produced abundant orange conidial mass on the medium. Conidia formed on PDA were pale brown, falcate, and 25.9 (17.1 to 34.3$) \mu \mathrm{m}$ long by 5.8 (4.3 to 7.1 ) $\mu \mathrm{m}$ wide. Setae were rarely produced on PDA but abundantly on malt sucrose agar (MSA), where they were dark brown, two to five septate, and 101.3 (65.7 to 148.6) $\mu \mathrm{m}$ long by 4.6 (2.9 to 5.7) $\mu \mathrm{m}$ wide (Table 1).

Pathogenicity of C. graminicola KA001 on barnyard grass and rice. The fungus infected both varieties of barnyard grass and exhibited symptoms similar to those observed in the fields over a wide range of growth stages. Disease symptoms developed as small, black spots on the leaves 3 days after inoculation. The lesions were followed by necrosis around the spots and progressed rapidly (Fig. 1). Barnyard grass at the three- to four-leaf stage was more heavily infected compared with other growth stages $(P<0.01$; Fig. 2$)$. Disease severity increased with increasing inoculum density from $1 \times 10^{4}$ to $1 \times 10^{5}$ con$\mathrm{idia} / \mathrm{ml}$, but inoculum density above $1 \times$ $10^{6}$ conidia/ml did not increase the disease severity $(P<0.01$; Fig. 3$)$. The two varieties of barnyard grass did not exhibit significant differences in disease development by this fungus $(P>0.05)$. None of the 13 rice cultivars exhibited disease symptoms on the leaves or stems 7 days after inoculation.

Host range of $C$. graminicola KA001. Three crops (corn, rye, and barley) and two weed species (henry crabgrass and goosefoot) were infected by $C$. graminicola KA001. Corn, rye, and goosefoot were infected at moderate levels (approximately 30 to $60 \%$ ), and barley and henry crabgrass were lightly infected (approximately 1 to $30 \%$ ). Soybean, alfalfa, panicum, red clover, and white clover had no disease symptoms (Table 2).

Conidial germination, mycelial growth, and sporulation of $C$. graminicola KA001. High levels of conidial germination (>80\%) were observed over a wide range of temperatures $\left(20\right.$ to $30^{\circ} \mathrm{C}$ ) on PDA, but the frequency of conidial germination was dramatically decreased at $15^{\circ} \mathrm{C}(29.2 \%$; Fig. 4A). Mycelial growth of C. graminicola KA001 was measured at different temperatures $\left(15,20,25,27\right.$, and $\left.30^{\circ} \mathrm{C}\right)$ on PDA. Mycelial growth was greater at higher temperatures $\left(25\right.$ and $\left.30^{\circ} \mathrm{C}\right)$ than at lower temperatures $\left(15\right.$ and $20^{\circ} \mathrm{C}$; Fig. $\left.4 \mathrm{~B}\right)$. No detectable mycelial growth was ob- 
served below $10^{\circ} \mathrm{C}$. The ability to sporulate was greatest at $27^{\circ} \mathrm{C}\left(2.3 \times 10^{7}\right.$ conidia/ml $)$ and poor at $15^{\circ} \mathrm{C}\left(3.1 \times 10^{5}\right.$ conidia/ml; Fig. 4C).

Histology of infection. To understand the selectivity between barnyard grass and rice, infection structure (appressorium) formation was observed on both plant leaves. Conidia of C. graminicola KA001 inoculated on the leaves of barnyard grass germinated and germ tubes differentiated into appressoria until $24 \mathrm{~h}$. Appressoria were formed preferentially on the anticlinal areas between the cells and on the stomatal pores. Penetration hyphae developed from appressoria were observed within the cells and a mass of infection hyphae progressed into the cells. The surrounding infected cells became necrotic and discolorized by this time. Numerous conidia and setae were produced from the infected lesions on barnyard grass leaves when infected leaves were placed under conditions of high humidity (Fig. 5). In contrast, appressoria were formed on the rice leaves, but infection hyphae were not found in the cells even after 7 days. Appressorium formation of $C$. graminicola KA001 was also induced on GelBond. No significant difference in the frequency of appressorium formation was observed on hydrophobic and hydrophilic surfaces of the GelBond $(P>0.05)$. A high frequency of conidial germination

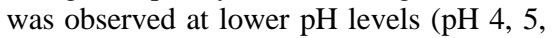
6 , and 7), while the highest frequency of appressorium formation was induced at $\mathrm{pH}$ 8 on the GelBond (Fig. 6). Appressorium formation was completely inhibited by the addition of IBMX or $\mathrm{N}^{6}$-monobutyryl cAMP, while $34.2 \pm 6.0 \%$ of germinated conidia formed appressoria in the control. The frequency of conidial germination was increased in the presence of IBMX (78.8 \pm $3.5 \%)$ or $\mathrm{N}^{6}$-monobutyryl cAMP (83.2 \pm $3.8 \%$ ), compared to the control (49.2 \pm $8.7 \%)$.

\section{DISCUSSION}

Several species of Colletotrichum have been extensively studied as mycoherbicides for controlling weeds in agronomic fields. A commercial mycoherbicidal product, Collego, has been developed from $C$. gloeosporioides f. sp. aeschynomene to control jointvetch $(7,27)$. C. graminicola has been reported to infect barnyard grass (28), but no attempt has been made to evaluate its potential as a mycoherbicidal candidate. We evaluated $C$. graminicola KA001 obtained from barnyard grass

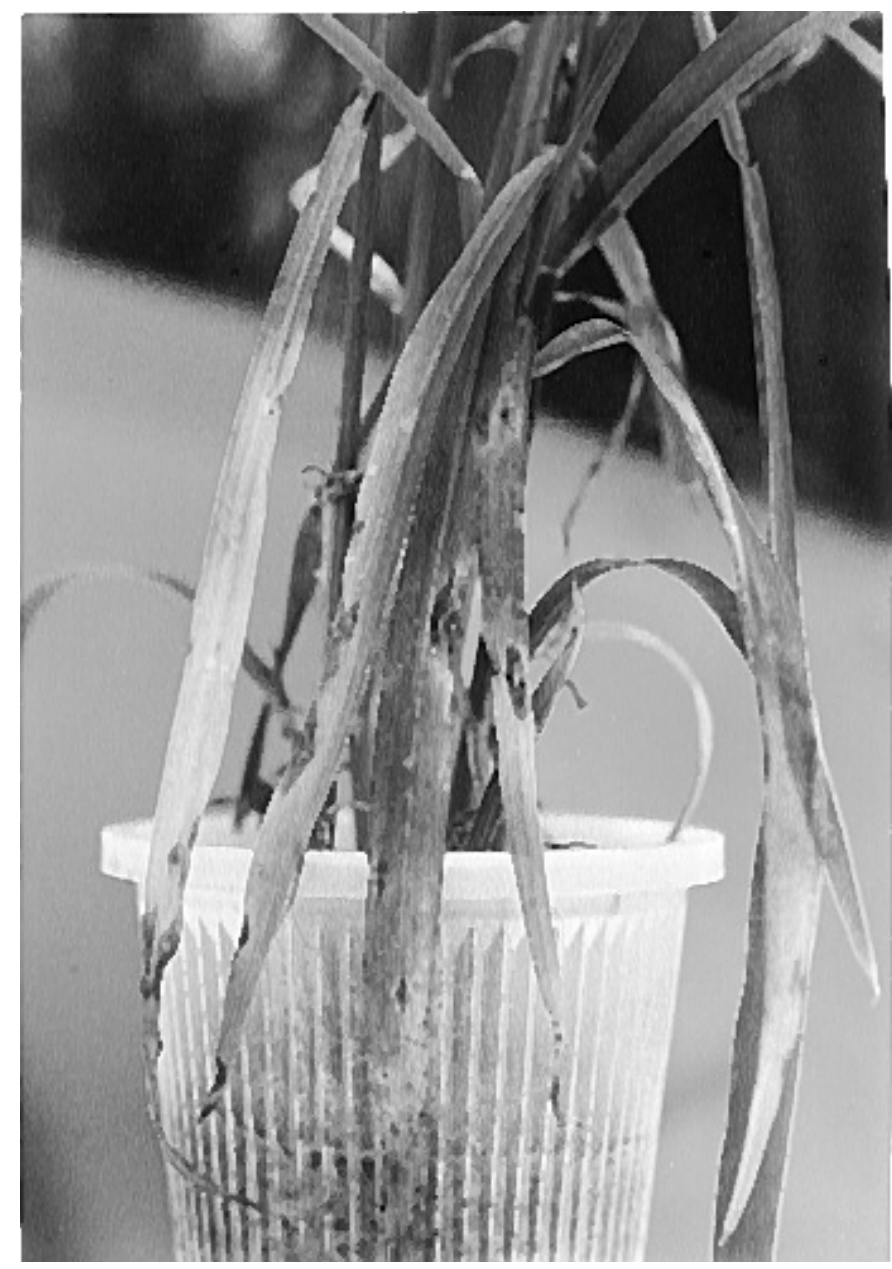

Fig. 1. Disease symptoms on barnyard grass (Echinochloa crus-galli var. caudata) leaves 7 days after inoculation with Colletotrichum graminicola KA001. showing anthracnose symptoms in rice fields as a mycoherbicide to control barnyard grass. Mycological characteristics of C. graminicola KA001, such as colony morphology and color, and microscopic observation of conidia and setae were similar to those reported from other hosts $(5,16,26)$.

C. graminicola KA001 showed strong pathogenicity in a wide range of growth stages of two barnyard grass varieties up to the six-leaf stage, with the strongest at three- to four-leaf stages. These results suggest that this fungus has potential as a mycoherbicide with a relatively wide application window to control barnyard

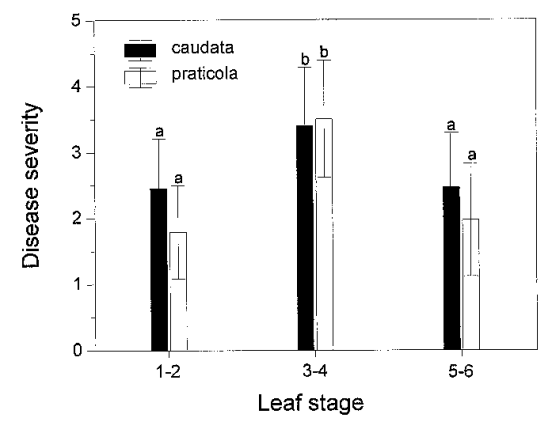

Fig. 2. Disease severity of two varieties of barnyard grass (Echinochloa crus-galli var. praticola and E. c. var. caudata) when inoculated at three different growth stages by Colletotrichum graminicola KA001. Disease severity was rated 7 days after inoculation using the following scale: $0=$ no disease, $1=1$ to $20 \%$ diseased, $2=21$ to $50 \%$ diseased, $3=51$ to $70 \%$ diseased, $4=71$ to $90 \%$ diseased, and $5=$ plants killed. Error bars represent standard deviation. Different letters above error bars represent significant difference of the means at $P=0.05$ according to Duncan's multiple range test.

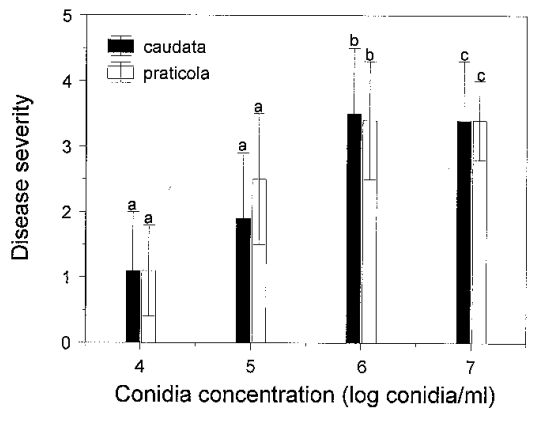

Fig. 3. Disease severity of two varieties of barnyard grass (Echinochloa crus-galli var. praticola and E. c. var. caudata) when inoculated by Colletotrichum graminicola KA001 with different conidial concentrations. Disease severity was rated 7 days after inoculation using following scale: $0=$ no disease, $1=1$ to $20 \%$ diseased, $2=21$ to $50 \%$ diseased, $3=51$ to $70 \%$ diseased, $4=71$ to $90 \%$ diseased, and 5 $=$ plants killed. Error bars represent standard deviation. Different letters above error bars represent significant difference of the means at $P=0.05$ according to Duncan's multiple range test. 
grass. The fact that this fungus was also pathogenic on other weed species, including crabgrass and goosefoot, would be advantageous in developing this fungus as a mycoherbicide. Furthermore, no detectable symptoms were observed on 13 rice cultivars inoculated with this fungus. Although this fungus also infected corn and rye, it may not be a limiting factor to its development as a mycoherbicide to apply in rice fields.

This fungus produced abundant conidia in culture over a wide temperature regime ranging from 20 to $30^{\circ} \mathrm{C}$. The optimum temperature for conidial germination and mycelial growth $\left(30^{\circ} \mathrm{C}\right)$ was similar to that of other mycoherbicidal Colletotrichum spp. $(10,14)$. This also suggests that this fungus is suitable for the development as a mycoherbicide with a wide application window as well as for mass production of inoculum.

Although appressorium formation was induced both on rice and barnyard grass leaves, infection hyphae were only observed in barnyard grass leaves. This suggests that $C$. graminicola KA001 cannot infect rice, although an infection structure was developed. These data also suggest that appressorium formation of $C$. graminicola KA001 is not host specific. Appressorium formation by this fungus on rice leaves may play a role in inducing a general resistance in rice against other pathogenic attacks. Recently, it has been demonstrated that an antagonistic yeast (Pichia guiliermondii US-7), which is effective in controlling a wide variety of postharvest rots of fruits, was capable of inducing a resistance response by inducing phenylalanine ammonia lyase in host tissues (29). It requires further research to determine whether appressorium formation by this non-pathogenic fungus on rice leaves induces defense-related responses. If this is the case, it would be a great advantage to develop this fungal pathogen as a mycoherbicide to control barnyard grass in the rice fields.

Appressorium formation of C. graminicola KA001 was also induced on artificial substrata, including flat and ridged, hydro- phobic and hydrophilic surfaces. This is somewhat different from other plant pathogenic fungi extensively studied in appressorium formation. Uromyces appendiculatus forms appressoria only on ridged surfaces, while hydrophobicity of the contact surface is required for Magnaporthe grisea to form appressoria $(18,22)$. The effect of chemicals $\left(\mathrm{N}^{6}\right.$-monobutyryl cAMP and IBMX) on appressorium formation of $C$. graminicola were different from those observed in M. grisea $(13,22)$. These data suggest that different fungi employ different mechanisms to infect their hosts, but the precise mechanisms remain to be elucidated.

We reported here that $C$. graminicola KA001 has potential as a biocontrol agent

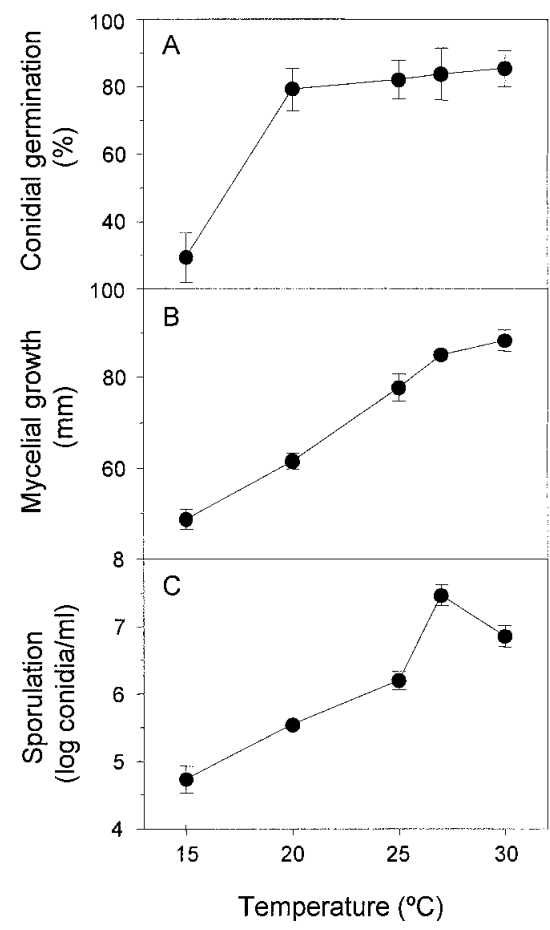

Fig. 4. (A) Conidial germination, (B) mycelial growth, and (C) sporulation of Colletotrichum graminicola KA001 on potato dextrose agar at different temperatures. Error bars represent standard deviation. to control barnyard grass in the rice fields. However, further research is required for the practical development of this fungus as a mycoherbicide, such as mass production of the inoculum, storage and formulation, and the possibility of combining with chemical herbicides.

\section{ACKNOWLEDGMENTS}

We thank C. S. Lee for advice on the statistical analysis.

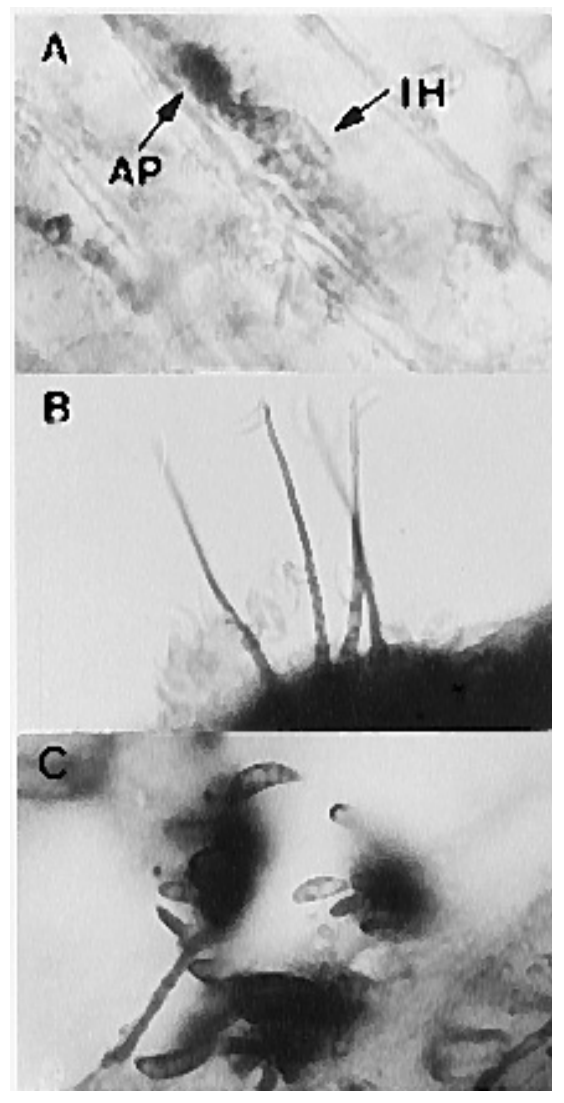

Fig. 5. Infection structures on barnyard grass leaves after inoculation by Colletotrichum graminicola KA001. (A) Appressorium and infection hyphae developed in the leaves. (B) Setae and (C) conidia were observed when inoculated leaves were incubated in a moist chamber. $\mathrm{AP}=$ appressorium and $\mathrm{IH}=$ infection hyphae.

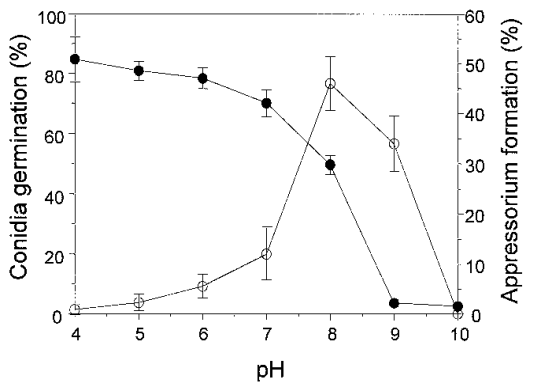

Fig. 6. Conidial germination and appressorium formation of Colletotrichum graminicola KA001 on the GelBond at different $\mathrm{pH}$ levels. Error bars represent standard deviation. 0 Conidial germination and $\bigcirc=$ appressorium formation.
Table 2. Pathogenicity of Colletotrichum graminicola KA001 on crops and weeds

\begin{tabular}{lc}
\hline Tested plants & Disease severity $^{\mathbf{a}}$ \\
\hline Crops & ++ \\
Corn (Zea mays cv. Kwanganock) & - \\
Soybean (Phaseolus vulgaris cv. Changsoo) & ++ \\
Rye (Avena sativa) & + \\
Barley (Hordeum vulgare cv. Tongbori) & - \\
Weeds & + \\
Alfalfa (Medicago sativa) & ++ \\
Henry crabgrass (Digitaria saguinalis) & - \\
Goosefoot (Chenopodium quinoa) & - \\
Panicum (Panicum bisulcatum) & - \\
Red clover (Trifolium pratense) & + \\
White clover (Trifolium repens) & \\
\hline
\end{tabular}

${ }^{\text {a }}$ Disease severity was assessed 7 days after inoculation. $-=$ No disease, $+=0$ to $30 \%$ diseased, $++=$ 30 to $60 \%$ diseased, and $+++=>60 \%$ diseased 


\section{LITERATURE CITED}

1. Adams, E. B., and R. F. Line. 1984. Epidemiology and host morphology in the parasitism of rush skeleton weed by Puccinia chondrillina. Phytopathology 74:745-748.

2. Alan, K. W. 1991. The classical approach with plant pathogens. Pages 3-23 in: Microbial Control of Weeds. D. O. TeBeest, ed. Chapman and Hall, London.

3. Auld, B. A., McRae, C. F., and Say, M. M. 1988. Possible control of Xanthium spinosum by a fungus. Agric. Ecosyst. \& Environ. 21:219-223

4. Barreto, R. W., and Evans, H. C. 1988. Taxonomy of a fungus introduced into Hawaii for biological control of Ageratina riparia (Eupatorieae; Compositae) with observations on related weed pathogens. Trans. Br. Mycol. Soc. 91:81-97.

5. Baxter, A. P., Van der Westhuizen, G. C., and Elicker, A. 1983. Morphology and taxonomy of South African isolates of Colletotrichum. S. Afr. J. Bot. 2:295-289.

6. Blanchette, B. L., and Lee, G. A. 1981. The influence of environmental factors on infection of rush skeleton weed (Chondrilla juncea) by Puccinia chondrillina. Weed Sci. 29:364-367.

7. Bowers, R. C. 1986. Commercialization of Collego-An industrialist's view. Weed Sci. 34 (Suppl.):24-25.

8. Boyette, C. D. 1991. Host range and virulence of Colletotrichum truncatum, a potential mycoherbicide for hemp sesbania (Sesbania exaltata). Plant Dis. 75:62-64.

9. Boyette, C. D., Templeton, G. E., and Smith, R. J., Jr. 1979. Control of winged water primrose (Jussiaea decurrens) and northern joint vetch (Aeschynomene virginica) with fungal pathogens. Weed Sci. 27:497-501.

10. Cartwright, D. K., and Templeton, G. E. 1992. Preliminary assessment of Colletotrichum capsici as a potential mycoherbicide for control of pitted morning-glory. Plant Dis.
76:995-998.

11. Charudattan, R. 1991. The mycoherbicide approach with plant pathogens. Pages 24-56 in: Microbial Control of Weeds. D. O. TeBeest, ed. Chapman and Hall, London.

12. Chiang, M. Y., Van Dyke, C. G., and Leonard, K. J. 1989. Evaluation of endemic foliar fungi for potential biological control of johnsongrass (Sorghum halepense): Screening and host range tests. Plant Dis. 73:459-464.

13. Choi, W. B., Kang, S. H., Lee, Y. W., and Lee, Y. H. 1998. Cyclic AMP restores appressorium formation inhibited by polyamines in Magnaporthe grisea. Phytopathology 88:5862.

14. Daniel, J. T., Templeton, G. E., Smith, R. J., Jr., and Fox, W. T. 1973. Biological control of northern jointvetch in rice with an endemic fungal disease. Weed Sci. 21:303-307.

15. Emge, R. G., Melching, J. S., and Kingsolver, C. H. 1981. Epidemiology of Puccinia chondrillina, a rust pathogen for the biological control of rush skeleton weed in the United States. Phytopathology 71:839-843.

16. Farr, F. D., Bills, F. G., Chamuris, P. G., and Rossman, Y. A. 1989. Fungi on Plant and Plant Products in the United States. APS Press, St. Paul, MN.

17. Guh, J. O., and Im, I. B. 1992. Change in weed problems as influenced by transition of cultural pattern into direct seeding. Kor. J. Weed Sci. 12:223-229.

18. Hoch, H. C., and Staples, R. C. 1987. Structural and chemical changes among the rust fungi during appressorium development. Annu. Rev. Phytopathol. 25:231-247.

19. Kim, S. C. 1992. Weed ecology and effective weed control technology in direct-seeded rice. Kor. J. Weed Sci. 12:230-260.

20. Kim, S. C., and Keith, M. 1989. Germination and seeding development of rice and Echinochloa species. Kor. J. Weed Sci. 9:108-115.

21. Kirkpatrick, T. L., Templeton, G. E., TeBeest,
D. O., and Smith, R. J., Jr. 1982. Potential of Colletotrichum malvarum for biological control of prickly sida. Plant Dis. 66:323-325.

22. Lee, Y. H., and Dean, R. A. 1993. cAMP regulates infection structure formation in the plant pathogenic fungus Magnaporthe grisea. Plant Cell 5:693-700.

23. McRae, C. F., and Auld, B. A. 1988. The influence of environmental factors on anthracnose of Xanthium spinosum. Phytopathology. 78:1182-1186.

24. Raid. R. N., and Pennypacker, S. P. 1987. Weeds as hosts for Colletotrichum coccodes. Plant Dis. 71:643-646.

25. Sung, S. S., Leather, G. R., and Hale, M. G. 1987. Induction of germination in dorman barnyardgrass (Echinochloa crus-galli) seeds by wounding. Weed Sci. 35:753-757.

26. Sutton, B. C. 1980. The Coelomycetes: Fungi Imperfecti with Pycnidia, Acervuli and Stromata. Commonw. Mycol. Inst., Kew, Surrey, Eng.

27. TeBeest, D. O., Yang, X. B., and Cisar, C. R. 1992. The status of biological control of weeds with fungal pathogens. Annu. Rev. Phytopathol. 30:637-657.

28. Wheeler, H., Politis, D. J., and Poneleit. 1974 Pathogenicity, host range, and distribution of Colletotrichum graminicola on corn. Phytopathology 64:293-296.

29. Wilson, C. L., Ghaouth, A. E., Chalutz, E. Droby, S., Stevens, C., Lu, J. Y., Khan, V., and Arul, J. 1994. Potential of induced resistance to control postharvest diseases of fruits and vegetables. Plant Dis. 78:837-844.

30. Wolf, G., and Fric, F. 1981. A rapid method for staining Erysiphe graminis f. sp. hordei in and on whole barley leaves with a protein specific dye. Phytopathology 71:596-598.

31. Wymore, L. A., Poirier, C., Watson, A. K., and Gotlieb, A. R. 1988. Colletotrichum coccodes, a potential bioherbicide for control of velvetleaf (Abutilon theophrasti). Plant Dis. 72:534-538. 